\title{
Exploring targeted therapy of osteosarcoma using proteomics data
}

This article was published in the following Dove Press journal:

OncoTargets and Therapy

I February 2017

Number of times this article has been viewed

\author{
Parunya Chaiyawat' \\ Jongkolnee Settakorn ${ }^{2}$ \\ Apiruk Sangsin' \\ Pimpisa Teeyakasem ${ }^{\prime}$ \\ Jeerawan Klangjorhor' \\ Aungsumalee Soongkhaw ${ }^{2}$ \\ Dumnoensun Pruksakorn ${ }^{1,3}$ \\ 'Orthopedic Laboratory and Research \\ Netting Center, Department of \\ Orthopedics, ${ }^{2}$ Department of \\ Pathology, Faculty of Medicine, \\ ${ }^{3}$ Excellence Center in Osteology \\ Research and Training Center, Chiang \\ Mai University, Chiang Mai, Thailand
}

Correspondence: Dumnoensun Pruksakorn

Orthopedic Laboratory and Research

Netting Center, Department of

Orthopedics, Faculty of Medicine,

Chiang Mai University, Chiang Mai 50200,

Thailand

Tel +6653935544

Fax +6653936442

Email dumnoensun.p@cmu.ac.th
Abstract: Despite multimodal therapeutic treatments of osteosarcoma (OS), some patients develop resistance to currently available regimens and eventually end up with recurrent or metastatic outcomes. Many attempts have been made to discover effective drugs for improving outcome; however, due to the heterogeneity of the disease, new therapeutic options have not yet been identified. This study aims to explore potential targeted therapy related to protein profiles of OS. In this review of proteomics studies, we extracted data on differentially expressed proteins (DEPs) from archived literature in PubMed and our in-house repository. The data were divided into three experimental groups, DEPs in 1) OS/OB: OS vs osteoblastic (OB) cells, 2) metastasis: metastatic vs non-metastatic sublines plus fresh tissues from primary OS with and without pulmonary metastasis, and 3) chemoresistance: spheroid (higher chemoresistance) vs monolayer cells plus fresh tissues from biopsies from good and poor responders. All upregulated protein entities in the list of DEPs were sorted and cross-referenced with identifiers of targets of US Food and Drug Administration (FDA)-approved agents and chemical inhibitors. We found that many targets of FDA-approved antineoplastic agents, mainly a group of epigenetic regulators, kinases, and proteasomes, were highly expressed in OS cells. Additionally, some overexpressed proteins were targets of FDA-approved non-cancer drugs, including immunosuppressive and antiarrhythmic drugs. The resulting list of chemical agents showed that some transferase enzyme inhibitors might have anticancer activity. We also explored common targets of OS/OB and metastasis groups, including amidophosphoribosyltransferase (PPAT), L-lactate dehydrogenase B chain (LDHB), and pyruvate kinase M2 (PKM2) as well as the common target of all categories, cathepsin D (CTSD). This study demonstrates the benefits of a text mining approach to exploring therapeutic targets related to protein expression patterns. These results suggest possible repurposing of some FDA-approved medicines for the treatment of OS and using chemical inhibitors in drug screening tests.

Keywords: osteosarcoma, proteomics, targeted therapy, text mining, FDA-approved drugs

\section{Introduction}

Osteosarcoma (OS) is the most common primary tumor of bone and has a high incidence in children and adolescents. ${ }^{1}$ An overall incidence is accounted for one to three per million annually worldwide. Multimodal treatment of OS currently includes surgery and multi-agent chemotherapy (ie, doxorubicin, cisplatin, and methotrexate), which results in an overall survival of $\sim 60 \%-70 \%$ in patients with localized disease. ${ }^{2}$ Nevertheless, for the past three decades, the 5-year survival rate of patients with metastasis remained stable at 30\%. ${ }^{3}$ The survival expectancy of OS patients with poor response to preoperative chemotherapy is even lower compared to the good responders. ${ }^{4}$ An effective therapy is a need to improve survival of those patients with unfavorable prognosis. 
Many attempts have been made to develop targeted medicines with low levels of adverse effects, which confer benefits to individual patients. Some clinical trials of targeted medicines in OS patients showed an improvement of outcome in subgroups of patients, whereas others demonstrated only low or no response (https://ClinicalTrials.gov). This lack of effectiveness is mainly due to OS genomic instability, the result of as yet unidentified driver genes. ${ }^{5}$ Dramatic heterogeneity of OS exists both among patients and in intra-tumor masses. Whole-genome sequencing (WGS) of OS specimens has revealed a high rate of somatic structural variation and gene copy number alterations. ${ }^{6}$ Various oncogenic pathways have been reported to be involved in the pathogenesis of this disease. All these facts suggest that to improve a response to targeted therapy in OS, it will be necessary to be able to match the right patient with the right treatment.

In an era of an advanced "omics" technology and big data analysis, proteomics is a major technique of choice for studying proteins expressed by certain types of cancer. ${ }^{7}$ Aberrant protein expression is an important characteristic of malignant transformation that involves changes in various cellular processes. ${ }^{8}$ Not only does proteomics determine the alteration of protein abundance, it also serves as a valuable tool for investigating diversity of proteomes, which arise largely from alternative splicing and post-translational modification. ${ }^{9}$ This technique allows scientists to gain additional insights into the molecular mechanisms that relate to oncogenic pathways.

This study aims to explore potential targeted therapy related to protein profiles of OS that possibly determine oncogenic phenotypes. To target putative oncogenic drivers, the list of up-regulated proteins was cross-referenced with antineoplastic agents approved by the US Food and Drug Administration (FDA). This method identified a potential targeted therapy based on an oncogene addiction model. This study also provided likely new targets for the treatment of OS using a drug repurposing approach. Interestingly, many groups of non-FDA-approved protein inhibitors were also explored as candidates for targeted therapy of OS. Based on these findings, we suggest further experimental testing of FDA-approved medicines for the treatment of OS and reveal possible uses of chemical agents as anticancer modality.

\section{Methods}

\section{Literature on mining of proteomics of OS}

In this study, we searched proteomics of OS data through the PubMed database using the search term "osteosarcoma AND Proteomics” for articles available before January 31, 2016.
Studies that examined non-human models were excluded. All proteomics information on OS cell lines and tissue specimens were retrieved and categorized according to their comparative models. Those models are 1) OS/OB: OS vs osteoblastic (OB) cells, 2) metastasis: metastatic vs nonmetastatic sublines plus fresh tissues from primary OS with and without pulmonary metastasis, and 3 ) chemoresistance: spheroid (higher chemoresistance) vs monolayer cells plus fresh tissues from biopsies from good and poor responders. Differentially expressed proteins (DEPs) with significant statistical power were extracted from the original articles as well as from supplementary data sources. Identifiers of genes and/or proteins that were not provided in the articles were added to the list by searching the UniProt database.

\section{Annotation of biological functions and pathways of DEPs}

To explore enriched biological functions and pathways of DEPs, we used an available bioinformatics approach for proteomics data analysis. Biological processes relating to DEPs were designated as Gene Ontology (GO) entities following the GO database released May 20, 2016. ${ }^{10}$ Cluster analysis of DEPs regarding their related biological process was also performed using the PANTHER classification system Version 10.0 released May 15, 2015. ${ }^{11}$ Pathway information from the KEGG and BIOCARTA databases was accessed via DAVID Bioinformatics Resources 6.7. ${ }^{12}$

\section{Generating lists of therapeutic targets in OS}

Up-regulated proteins were sorted from the list of DEPs in each of the experimental groups (OS/OB, metastasis, and chemoresistance). The proteins were cross-referenced with lists of FDA-approved antineoplastic agents, FDA-approved non-antineoplastic agents, and non-FDA-approved chemical agents, reported elsewhere. ${ }^{13}$

\section{Results}

\section{Literature mining}

According to the PubMed database, proteomics studies of OS have been performed both in cell cultures and in clinical specimens including the study of 1) OS and OB cells, 2) OS and benign tumor tissues, 3) phenotypic characteristics of OS cells including metastasis and chemoresistance, 4) responsiveness to various medicines or specific induction, 5) OS cell lines, and 6) serum or plasma from OS patients (Table 1). The primary literature mining unveiled a number of DEPs. We found that DEPs in specific models 
Table I Proteomics studies of osteosarcoma in PubMed database

\begin{tabular}{ll}
\hline Proteomic study & $\begin{array}{l}\text { Number } \\
\text { of articles }\end{array}$ \\
\hline OS vs OB cells ${ }^{15-22}$ & 8 \\
OS vs benign bone tumor tissues ${ }^{49-53}$ & 5 \\
Metastasis vs non-metastasis $^{11,54-56}$ & 4 \\
Chemoresistance $^{57,58}$ & 2 \\
Responsiveness to various medicines $^{59-64}$ & 6 \\
Responsiveness under specific stimulus conditions $^{37,38}$ & 2 \\
OS cell lines $^{65-69}$ & 5 \\
Serum or plasma of OS patients & \\
Tota-74 & 5 \\
\hline
\end{tabular}

Abbreviations: OS, osteosarcoma; OB, osteoblastic.

might relate to molecular mechanisms of relapse events in OS patients, so we focus primarily on proteomics analysis of DEPs in three experimental groups: OS/OB, metastases, and chemoresistance.

Eight proteomics studies of OS/OB were published from 2006 through early 2016 (Table 2). Those proteomics studies of OS cells were performed mainly using a gel-based approach, and most studied biological mechanisms of the disease as well as seeking potential diagnostic biomarkers and novel therapeutic targets. From our previous work, we have performed proteomics study in primary OS cells $(n=7)$ and OB cells of cancellous bone ( $n=7)$ using two-dimensional gel electrophoresis (2DE) and liquid chromatography-tandem mass spectrometry (LC-MS/MS) analysis. ${ }^{14}$ We successfully identified DEPs in OS compared to OB cells. Therefore, to generate a list of DEPs in OS, proteomics data from literature and in-house results were combined. The end result was the successful identification of $\sim 2,300$ DEPs. ${ }^{15-22}$ Proteomics studies of metastatic and chemoresistant phenotypes of OS have previously been reported by different research groups (Tables 3 and 4). Although the number of publications on these events has been limited, we found that the data mined from text database resources were informative. Overall, 49 and 29 DEPs were identified in metastatic and chemoresistant studies, respectively. Most proteomics studies of metastases have been performed in cell culture experiments (Table 3). DEPs have been identified in non-metastatic and metastatic sublines that have included several models, including one report that examined DEPs in primary OS tissue with and without metastasis.

The list generated in this study also includes DEPs that exhibit chemoresistance. Proteomics studies of chemoresistance of OS included investigation of eleven OS cell lines treated with doxorubicin. Notably, DEPs resistant to doxorubicin were observed in most of the cells examined. Other papers have reported DEPs in frozen tissues of both good and poor responders before treatment with methotrexate, doxorubicin, and cisplatin. We included DEPs in both those groups as these identified proteins provide an indication of cellular responsiveness after chemotherapy. DEPs identified in these reports are potentially useful as biomarkers that may be able to predict chemotherapy responsiveness in OS.

\section{Enriched biological processes and pathways in OS}

To the list of DEPs identified from literature mining, we added information about each protein including gene entities (eg, from the UniProtKB database). DEPs in each of the experimental groups (OS/OB, metastasis, and chemoresistance) were additionally categorized on the basis of their biological processes using $\mathrm{GO}^{10}$ and were designated as $\mathrm{GO}$ terms

Table 2 Proteomics studies of OS/OB experimental groups

\begin{tabular}{|c|c|c|c|c|}
\hline \multicolumn{2}{|l|}{ Model } & \multirow[t]{2}{*}{ Techniques } & \multirow[t]{2}{*}{ Year } & \multirow[t]{2}{*}{ Citation } \\
\hline OB cells & OS cells & & & \\
\hline Primary cells: bone samples & OS cell line: SaOS-2 & 2DE, MALDI-TOF & 2006 & Spreafico et al ${ }^{15}$ \\
\hline OB cell line: hFOBI.I9 & $\begin{array}{l}\text { OS cell lines: U2OS, SaOS-2, and } \\
\text { IOR/OS9 }\end{array}$ & 2DE, MALDI-TOF & 2007 & Guo et $\mathrm{al}^{16}$ \\
\hline $\begin{array}{l}\text { Primary cells: corresponding } \\
\text { normal tissues from patients }\end{array}$ & $\begin{array}{l}\text { Primary OS cells: paired biopsy from } \\
\text { chemonaive high-grade patients }\end{array}$ & 2D-DIGE, LC-ESI-MS/MS & 2009 & Folio et al ${ }^{17}$ \\
\hline Primary cells: bone samples & OS cell line: $\mathrm{SaOS}-2$ & 2DE, MALDI-TOF & 2009 & Liu et $\mathrm{al}^{18}$ \\
\hline OB cell line: hFOBI.19 & OS cell line: MG-63 & iTRAQ labeling, LC-MS/MS & 2010 & Zhang et al ${ }^{19}$ \\
\hline OB cell line: hFOBI.19 & OS cell line: MG-63 & 2DE, ESI-MS/MS & 2011 & Hua et $\mathrm{al}^{22}$ \\
\hline $\begin{array}{l}\text { Primary OB cells: ORT-I, } \\
\text { Hum3I, and Hum54 }\end{array}$ & $\begin{array}{l}\text { OS cell lines: MG-63, U2OS, Cal-72, } \\
\text { SaOS-2, and LM7 }\end{array}$ & $\begin{array}{l}\text { IDE, LC-MS/MS, label-free } \\
\text { quantitative protein analysis }\end{array}$ & 2013 & PosthumaDeboer et $\mathrm{al}^{20}$ \\
\hline OB cell line: hFOBI.I9 & $\begin{array}{l}\text { OS cell lines: } \mathrm{Hs} \text { 39.T, Hs I84.T, } \\
\text { and } \mathrm{Hs} \text { I88.T }\end{array}$ & 2DE, TOF/TOF & 2015 & Gemoll et $\mathrm{a}^{21}$ \\
\hline
\end{tabular}

Abbreviations: OS, osteosarcoma; OB, osteoblastic; 2DE, two-dimensional gel electrophoresis; MALDI-TOF, matrix-assisted laser desorption/ionization time-of-flight mass spectrometry; 2D-DIGE, two-dimensional difference gel electrophoresis; iTRAQ, isobaric tags for relative and absolute quantitation; LC-MS/MS, liquid chromatographytandem mass spectrometry; ESI-MS/MS, electrospray ionization mass spectrometry; TOF/TOF, tandem time-of-flight. 
Table 3 Proteomics studies of metastasis in OS

\begin{tabular}{|c|c|c|c|c|}
\hline \multicolumn{2}{|l|}{ Model } & \multirow[t]{2}{*}{ Techniques } & \multirow[t]{2}{*}{ Year } & \multirow[t]{2}{*}{ Citation } \\
\hline Non-metastasis & Metastasis & & & \\
\hline OS cell lines: $\mathrm{HOS}, \mathrm{SaOS}-2$ & OS metastatic sublines: I43B, LM7 & A lectin column followed by MudPIT & 2012 & Flores et al ${ }^{54}$ \\
\hline Low-metastatic subline: F4 & Highly metastatic subline: F5M2 & 2D-DIGE, MALDI-TOF & 2014 & Chen et $\mathrm{a}^{55}$ \\
\hline OS tissue without metastasis & OS tissue with metastasized to lung & 2DE, MALDI-TOF & 2014 & Tang et al ${ }^{56}$ \\
\hline OB cell line: $\mathrm{hFOBI.19}$ & OS cell lines: $\mathrm{Hs}$ 39.T, $\mathrm{Hs}$ I84.T, and $\mathrm{Hs}$ I88.T & 2DE, TOF/TOF & 2015 & Gemoll et al ${ }^{2}$ \\
\hline
\end{tabular}

Abbreviations: OS, osteosarcoma; MudPIT, multidimensional protein identification technology; 2D-DIGE, two-dimensional difference gel electrophoresis; MALDI-TOF, matrix-assisted laser desorption/ionization time-of-flight mass spectrometry; 2DE, two-dimensional gel electrophoresis; TOF/TOF, tandem time-of-flight.

(Figure 1). It was found that more than half the DEPs in all the experimental groups were involved in metabolic and cellular processes. Lower pathway enrichment involved developmental processes, localization, biological regulation, etc. The diversity of these pathways varied slightly among the experimental groups. The complete list of biological processes is provided in the Supplementary materials.

Various functions of all DEPs that were related to signaling pathways were accessed through two pathway databases, KEGG and BIOCARTA, using the DAVID bioinformatics resource. It was found that DEPs in OS/OB were involved in pivotal metabolisms of molecular building blocks, including carbohydrates, amino acids, and nucleotides. Some played roles in genetic information processes including translation, transcription, replication, and repair, as well as folding, sorting, and degradation, whereas others were associated with cardiovascular diseases. By considering individual pathways (child categories), spliceosomes accounted for the most enriched pathways among all OS/OB DEPs according to the KEGG database (Figure 2). Additionally, the BIOCARTA database revealed an association between DEPs in OS with AKT/mTOR signaling pathways.

Due to the limited number of DEPs identified in metastases and chemoresistance, pathway analyses using KEGG pathways and BIOCARTA were not very revealing for most DEPs. However, we did find that most DEPs in metastatic outcomes were involved in both glycolysis/gluconeogenesis and pyruvate metabolism (Figure 3). Additionally, analysis of the BIOCARTA database revealed an association between DEPs and pathways of down-regulated MTA-3 in estrogen receptor (ER)-negative breast tumors. Small amounts of DEPs in chemoresistance were associated with several pathways including spliceosomes (Figure 3).

\section{Novel targets for the treatment of OS}

In this study, our ultimate aim was to use proteomics data to seek potential target remedies for precision treatment. All the up-regulated proteins extracted from the list of DEPs were converted to gene identifiers. The proteins were then cross-referenced with three groups of available medicines and chemical agents including FDA-approved antineoplastic drugs, FDA-approved non-antineoplastic drugs, and nonFDA-approved chemical agents. The result was 14, 5, and 37 proteins up-regulated in OS/OB that could be matched to FDA-approved antineoplastic drugs, FDA-approved non-antineoplastic drugs, and non-FDA-approved chemical agents, respectively. The flow of generating the list of targeted treatments is shown in Figure 4A.

We also found that several overexpressed proteins in the metastatic and chemoresistant groups were targets of either FDA-approved non-antineoplastic drugs or non-FDAapproved chemical agents. The resulting lists revealed that the target of the FDA-approved non-antineoplastic drug amidophosphoribosyltransferase (PPAT) was a common target of OS/OB and metastatic sublines (Figure 4B). In addition, targets of the non-FDA-approved chemical agents L-lactate dehydrogenase $\mathrm{B}$ chain (LDHB) and pyruvate kinase M2 (PKM2) were found as common targets between OS/OB and metastases, while cathepsin D (CTSD) was the intersected target of all scenarios. Glyceraldehyde-3-phosphate

Table 4 Proteomics studies of chemoresistance in OS

\begin{tabular}{|c|c|c|c|c|}
\hline Model & Treatment & Techniques & Year & Citation \\
\hline OS cell lines: HS-Os-I, NOS-I, SaOS-2, & Doxorubicin & 2D-DIGE, annotated mass & 2013 & Arai et $\mathrm{al}^{57}$ \\
\hline SJSA-I, I43B, HOS, HuO9, KHOS/NP, & & spectra in Genome Medicine & & \\
\hline MG-63, MNNG-HOS, and NOS-10 & & Database of Japan Proteomics & & \\
\hline $\begin{array}{l}\text { Frozen tissue: poor responders ( }<90 \% \\
\text { necrosis), good responders ( }>90 \% \text { necrosis) }\end{array}$ & $\begin{array}{l}\text { Methotrexate, doxorubicin, } \\
\text { and cisplatin }\end{array}$ & $\begin{array}{l}\text { 2D-DIGE, Orbitrap mass } \\
\text { spectrometer }\end{array}$ & 2013 & Kubota et al $\left.\right|^{58}$ \\
\hline
\end{tabular}

Abbreviations: OS, osteosarcoma; 2D-DIGE, two-dimensional difference gel electrophoresis. 

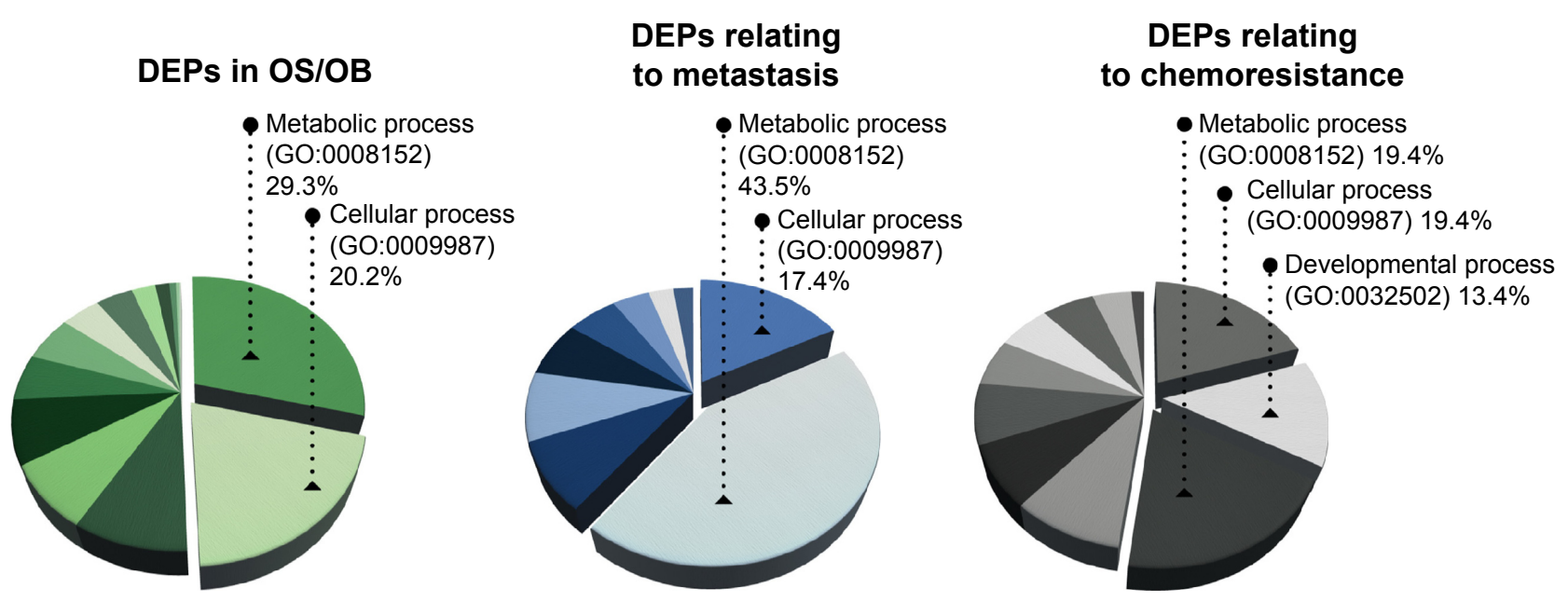

Figure I Enriched biological processes (GO annotation) of DEPs in OS/OB, metastasis, and chemoresistance. Abbreviations: GO, gene ontology; DEPs, differentially expressed proteins; OS, osteosarcoma; OB, osteoblastic.

dehydrogenase (GAPDH) was exclusively overexpressed in metastatic cells (Figure 4B). Details of individual targeted proteins and drugs are shown in Tables 5 and 6 and the Supplementary materials.

\section{Discussion}

In this study, we used bioinformatics tools to analyze proteomics data retrieved from "PubMed". It was found that "metabolic pathway" was the most enriched biological process of DEPs in the three experimental groups: 1) OS/OB: OS vs OB cells, 2) metastasis: OS with metastasis vs nonmetastasis, and 3) chemoresistance: OS with higher vs lower chemoresistance (Figure 1). Among those, the primary metabolic processes of proteins, nucleobase-containing compounds, lipids, carbohydrates, and amino acids were the most frequently altered. In addition, KEGG pathway analysis demonstrated that aberrant expression of proteins in the OS/OB group was mainly related to the "genetic information process", which consists of translation, transcription, replication, and repair, as well as folding, sorting, and degradation (Figure 2).

This study identified metabolic processes potentially associated with progression of the disease. Growing evidence of metabolic reprogramming in cancer cells has uncovered the important role of oncogenic signaling pathways in the regulation of metabolic activities. Cancer cells require more energy and need specific building blocks for macromolecule biosynthesis during growth and proliferation. All metabolic changes effectively support and maintain the uncontrollable growth, migration, and metastatic processes of cancer cells. However, it is worth noting that not all metabolic shifts are a consequence of oncogenic driven processes: they might possibly also reflect cellular adaptation to high proliferation rates.

In order to identify alternative targets for OS treatment, we sorted lists of up-regulated proteins from DEPs in each experimental group and then cross-referenced those with three groups of drugs and chemical agents. Overexpression of proteins in the OS/OB group defined as targets of FDA-approved antineoplastic drugs were classified into one of four categories based on their functions: 1) Epigenetic regulators: DNMT1, HDAC1, and HDAC2; 2) Kinases: ERBB2, FGFR1, KIT, MET, MTOR, and PDGFR $\alpha$; 3) Proteasomes: PSMC5 and PSMC6, and 4) Others: GSR and PARP1 (Table 5). These proteins have been previously studied as promising targets for the treatment of various cancer types including OS. Recently, Yu et $\mathrm{al}^{23}$ screened 54 FDA-approved agents for their antigrowth activity in five pediatric OS cell lines carrying p53 inactivation. Among the tested agents, inhibitors targeting HDACs (romidepsin and panobinostat) showed significant single-agent activity and synergistic effects when combined with proteasome inhibitors (carfilzomib and bortezomib) that work effectively within a range of clinically achievable concentrations.

Other promising oncogenic targets discovered in this study were tyrosine kinases. Attempts at using multi-kinase inhibitors for the treatment of OS were carried on in clinical trials. The outcomes were very promising as seen in Phase II clinical trials that assessed the effectiveness of sorafenib in patients with high-grade and unresectable OS. ${ }^{24,25}$ Those trials, which resulted in a $48 \%$ progression-free survival rate of patients at 4 months, demonstrated that sorafenib could potentially be used as a second- or third-line treatment. A small molecule kinase inhibitor, imatinib mesylate, 


\section{KEGG pathway}

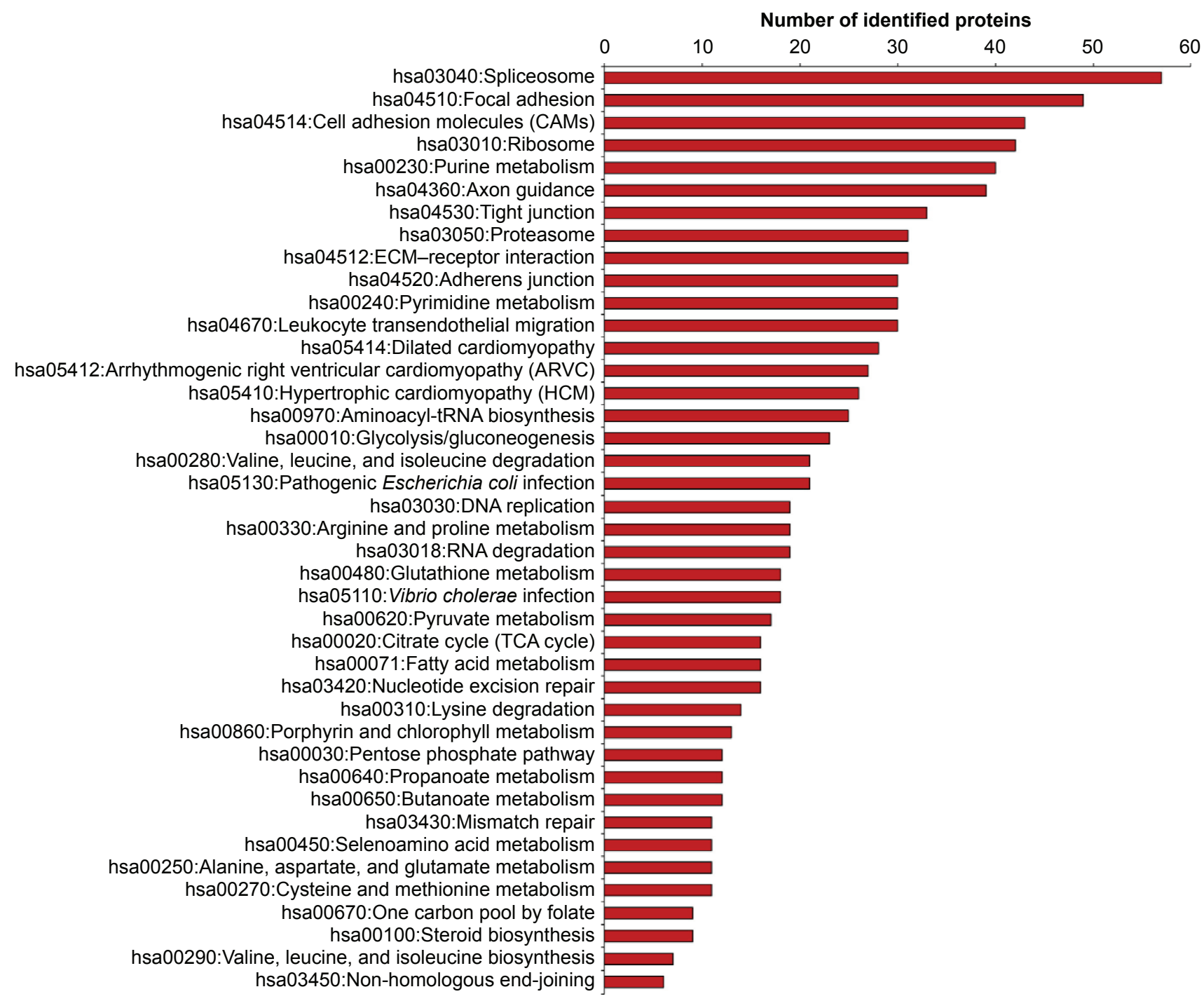

\section{BIOCARTA}

Number of identified proteins

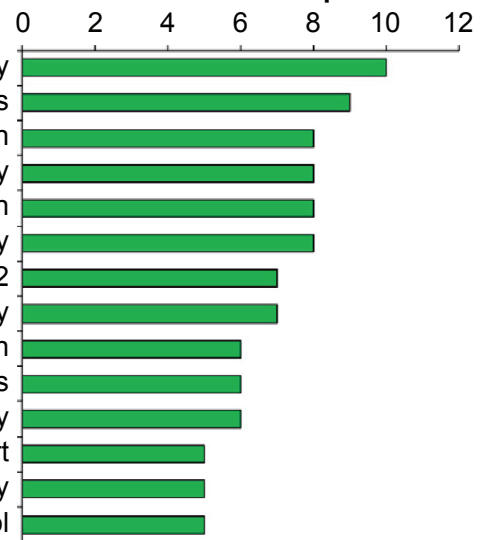

Shuttle for transfer of acetyl groups from mitochondria to the cytosol

Figure 2 Pathway analysis of DEPs in OS/OB (from KEGG and BIOCARTA databases).

Abbreviations: DEPs, differentially expressed proteins; OS, osteosarcoma; OB, osteoblastic; ECM, extracellular matrix; tRNA, transfer RNA; TCA, the tricarboxylic acid; $\mathrm{CBL}$, E3 ubiquitin-protein ligase CBL; EGF, epidermal growth factor. 


\section{DEPs in metastatic OS cells}

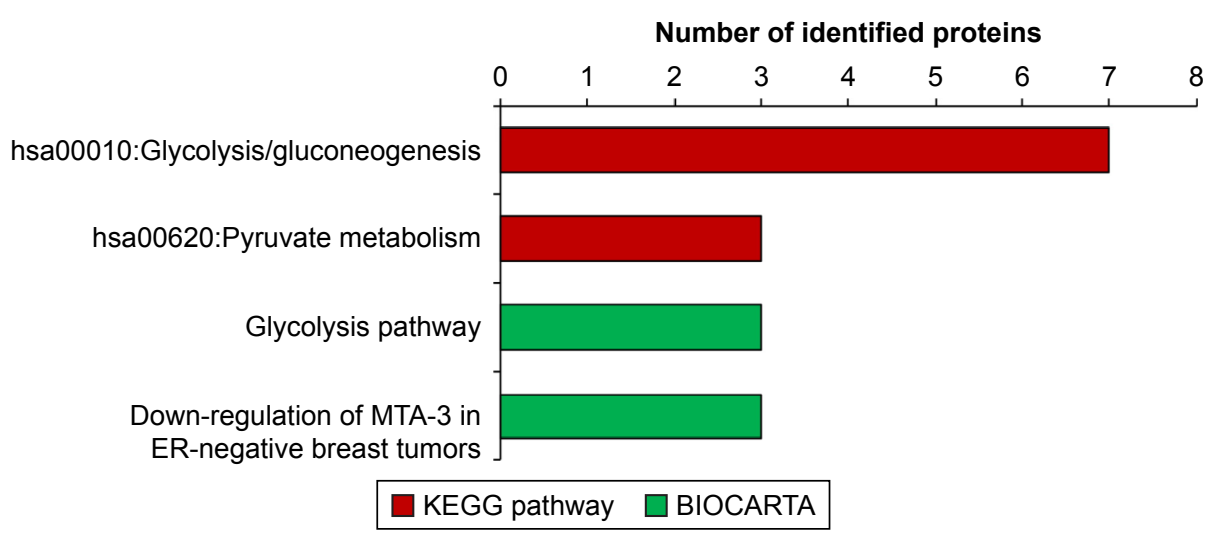

DEPs in chemoresistant OS cells

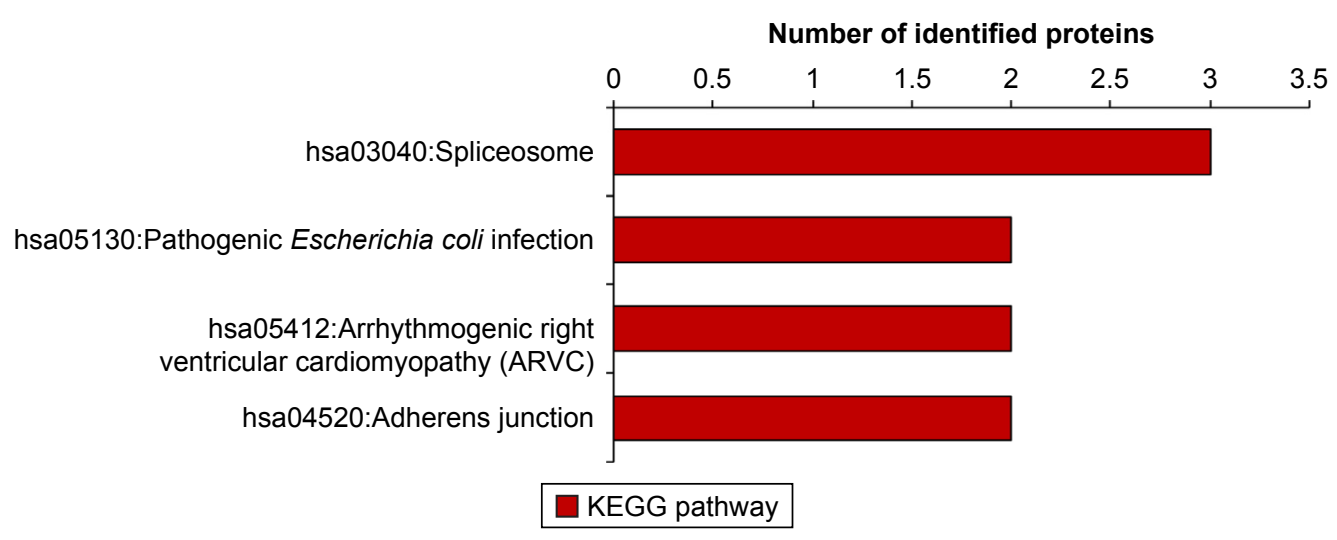

Figure 3 Pathway analysis of DEPs in metastasis and chemoresistance (from KEGG and BIOCARTA databases). ${ }^{75,76}$ Abbreviations: DEPs, differentially expressed proteins; OS, osteosarcoma; ER, estrogen receptor.

induced significant cytotoxic activity in OS primary cells that were overexpressing PDGFR $\alpha .^{26,27}$ Phase II clinical trials conducted in OS patients with recurrence, chemoresistance, or lung metastasis found moderately clinical responses in subgroup of patients. ${ }^{28,29}$ Ideally, experimental investigation of expression of tyrosine kinases is the prerequisite for selecting patients who will gain a true benefit from this targeted treatment. One of these trials examined the expression and mutation profiles of targeted kinases including “cKIT, PDGR $\alpha$, AKT, pAKT, PTEN, and pFKHR" in formalin-fixed, paraffin-embedded (FFPE) tissues from eligible patients. ${ }^{29}$ However, an association between the laboratory evaluation and a responsiveness to imatinib was not well established due to a limitation of available retained tissue samples. Therefore, further systemic experimental evaluation is necessary for suggesting therapeutic options to specific groups of patients. Other clinical trials of kinase inhibitors in
OS patients including pazopanib (Phase II; NCT01532687) and lenvatinib (Phase I/II; NCT02432274) are ongoing.

Carmustine works as an antagonist of GSR and as a DNA and RNA alkylator. ${ }^{30}$ The FDA has approved the use of carmustine in the treatment of brain tumors, multiple myeloma, Hodgkin's disease, and non-Hodgkin's lymphomas. Some evidence has indicated an antitumor activity of carmustine in androgen-independent prostate cancer cells and various human solid tumor cell lines. ${ }^{30,31}$ Another promising target is MET oncoprotein. Overexpression and amplification of MET have been observed frequently in OS, with this aberrancy associated with poorer outcomes. ${ }^{32}$ Moreover, it was found that up-regulation of MET potentially induced transformation of osteoblasts into OS carrying typical OS characteristics and neovascularization ability. ${ }^{33}$

The process of drug development starting from basic research through FDA approval normally requires $>10$ years 


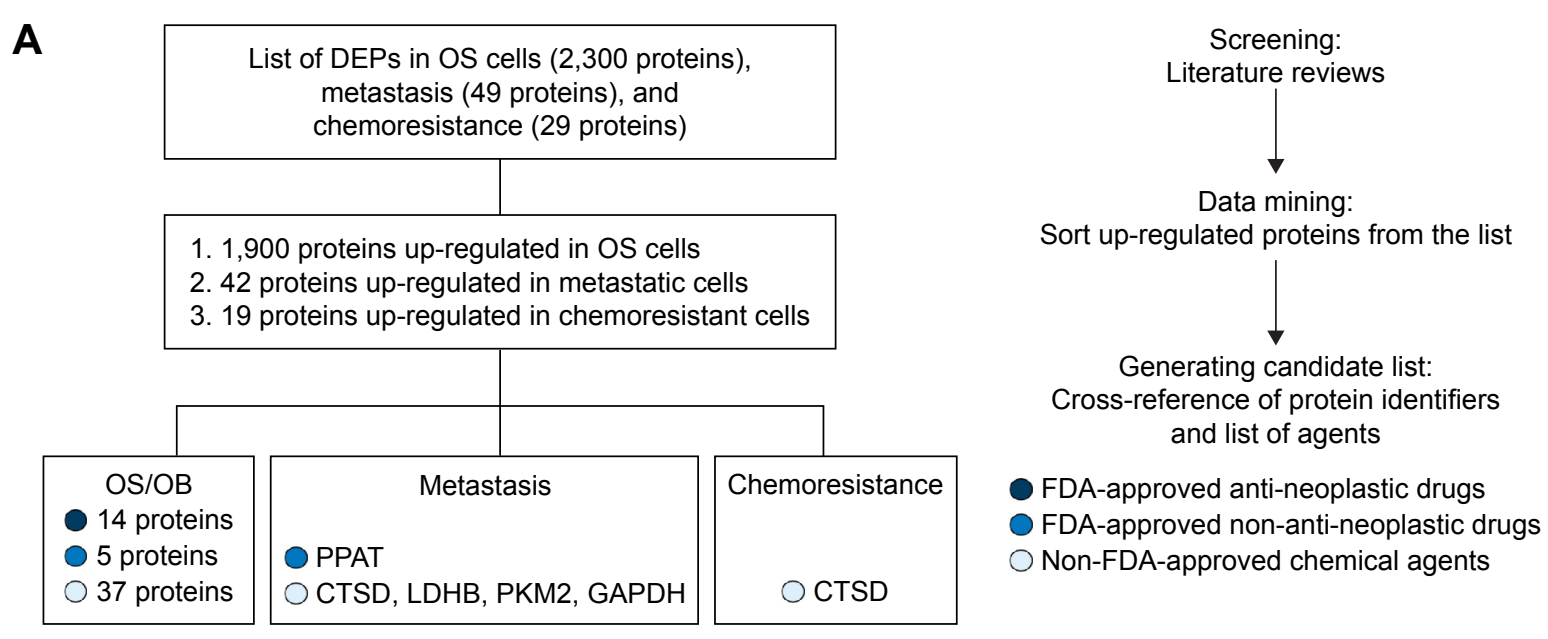

B

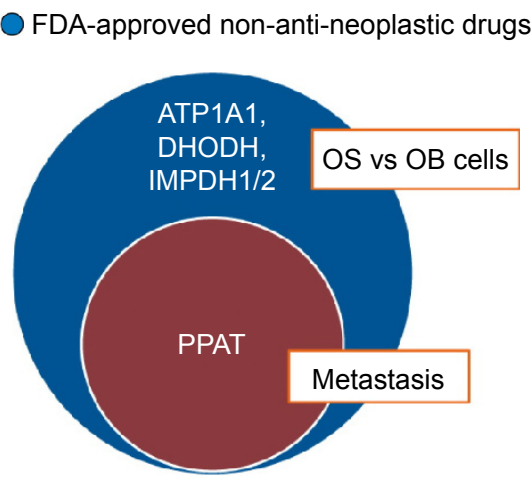

Non-FDA-approved chemical agents

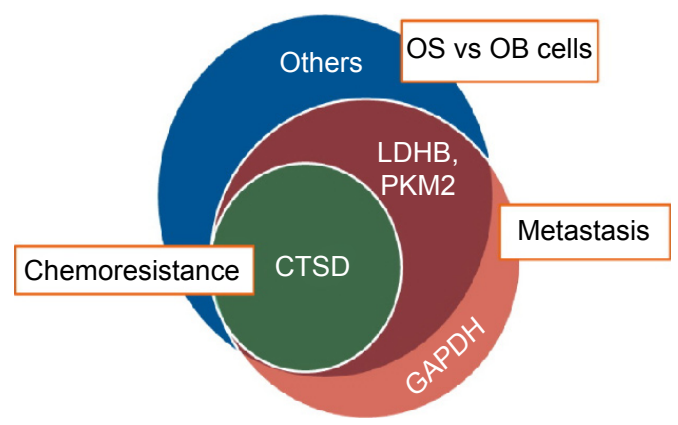

Figure 4 Generating the list of druggable targets for the treatment of OS: (A) overview of all steps used in generating the list and (B) diagrams of targets of FDA-approved non-antineoplastic drugs and non-FDA-approved chemical agents from studies of proteomics in three experimental groups.

Abbreviations: OS, osteosarcoma; FDA, Food and Drug Administration; DEPs, differentially expressed proteins; OB, osteoblastic; PPAT, amidophosphoribosyltransferase; CTSD, cathepsin D; LDHB, L-lactate dehydrogenase B chain; PKM2, pyruvate kinase M2; GAPDH, Glyceraldehyde-3-phosphate dehydrogenase.

and an average investment of US\$1.8 billion. ${ }^{34}$ Unfortunately, most new agents fail to reach the market stage due to a lack of efficacy in Phase II clinical trials. This issue in current cancer drug development has been addressed by scientific communities, with the result that the strategy of using approved non-cancer drugs for the treatment of various cancers (known as "drug repurposing" or "drug repositioning") has gained much attention ${ }^{35}$ as the necessary toxicity testing as well as pharmacokinetic and pharmacodynamics profile development has already been assessed and approved in the preclinical and Phase I clinical trials. Thus, the potential drugs are in a position to move into Phase II and III clinical trials within a shorter period and at a lower cost. This study has identified a group of immunosuppressant and antiarrhythmia agents that are promising candidates for the repurposing approach (Table 6).

Among the immunosuppressants, leflunomide is the likely candidate for repurposing as an anticancer agent. Leflunomide is an inhibitor of DHODH that, in turn, modulates pyrimidine synthesis that is a major target in the treatment of rheumatoid arthritis. ${ }^{36}$ Interestingly, this study found that the expression profile of DHODH was aberrant in some malignancies including OS. There is growing evidence of the anticancer activity of leflunomide in preclinical trials with neuroblastoma, medullary thyroid cancer, and other cancers. $^{36,37}$ Besides being a potent inhibitor of $\mathrm{DHOH}$, it has been reported that leflunomide also inhibits PDGFR and other tyrosine kinases. ${ }^{38}$ Using leflunomide in cancer therapy would likely be of great benefit since the direct relationship between tyrosine kinases and oncogenesis has been well documented.

In this study, we also explored the possibility that digoxin could be a potential candidate for repurposing. This drug is in a group of cardiac glycosides, an inhibitor of $\mathrm{Na}^{+} / \mathrm{K}^{+}$ATPase pump that has been commonly used in heart failure and which has worked as an antiarrhythmic. Treating cancer cell lines with digoxin resulted in cytotoxicity in several types of cancer cells including prostate, breast, renal, and lung cancers, melanoma, and leukemia. ${ }^{39}$ Notably, the $\mathrm{IC}_{50}$ of this drug in tests with the aforementioned cancer cells is 
Table 5 Up-regulated proteins and targets of FDA-approved antineoplastic drugs

\begin{tabular}{|c|c|c|c|}
\hline Gene & Protein name & FDA-approved drug & Disease indication $^{\mathrm{a}}$ \\
\hline \multirow[t]{2}{*}{ DNMTI } & DNA (cytosine-5)- & Azacitidine (Vidaza) & Myelodysplastic syndrome, chronic myelomonocytic leukemia \\
\hline & methyltransferase I & Decitabine (Dacogen) & Myelodysplastic syndrome \\
\hline \multirow[t]{5}{*}{ ERBB2 } & Receptor tyrosine-protein kinase & Trastuzumab (HERCEPTIN) & HER2-positive breast cancer \\
\hline & erbB-2 & Lapatinib (Tycerb) & $\begin{array}{l}\text { Advanced or metastatic breast cancer whose tumors } \\
\text { overexpress HER2 and who have received prior therapy } \\
\text { including an anthracycline, a taxane, and trastuzumab }\end{array}$ \\
\hline & & $\begin{array}{l}\text { Ado-trastuzumab emtansine } \\
\text { (KADCYLA) }\end{array}$ & $\begin{array}{l}\text { Including an anthracycline, a taxane, and trastuzumab } \\
\text { HER2-positive, metastatic breast cancer patients who have } \\
\text { already used taxane and/or trastuzumab for metastatic } \\
\text { disease or had their cancer recur within } 6 \text { months of } \\
\text { adjuvant treatment }\end{array}$ \\
\hline & & Afatinib (GILOTRIF) & $\begin{array}{l}\text { The first-line treatment of patients with metastatic NSCLC } \\
\text { whose tumors have EGFR exon } 19 \text { deletions or exon } 21 \\
\text { (L858R) substitution mutations as detected by an } \\
\text { FDA-approved test }\end{array}$ \\
\hline & & Pertuzumab (PERJETA) & $\begin{array}{l}\text { In combination with trastuzumab and docetaxel for the } \\
\text { treatment of patients with HER2-positive metastatic breast } \\
\text { cancer who have not received prior anti-HER2 therapy or } \\
\text { chemotherapy for metastatic disease }\end{array}$ \\
\hline GSR & $\begin{array}{l}\text { Glutathione reductase, } \\
\text { mitochondrial }\end{array}$ & $\begin{array}{l}\text { Carmustine (GLIADEL }{ }^{\circledR} \\
\text { WAFER) }\end{array}$ & $\begin{array}{l}\text { Brain tumors, multiple myeloma, Hodgkin's disease, and } \\
\text { non-Hodgkin's lymphomas }\end{array}$ \\
\hline $\mathrm{HDACl}$ & Histone deacetylase I & Vorinostat (Zolinza) & Cutaneous T-cell lymphoma \\
\hline HDAC2 & Histone deacetylase 2 & Romidepsin (Istodax) & $\begin{array}{l}\text { Cutaneous T-cell lymphoma with at least one prior systemic } \\
\text { therapy }\end{array}$ \\
\hline \multirow[t]{7}{*}{ KIT } & $\begin{array}{l}\text { Mast/stem cell growth factor } \\
\text { receptor kit }\end{array}$ & Imatinib mesylate (Gleevec) & $\begin{array}{l}\text { ALL, GIST, dermatofibrosarcoma protuberans, CML, } \\
\text { myelodysplastic syndrome }\end{array}$ \\
\hline & & Sorafenib (Nexavar) & Advance renal cell carcinoma, some hepatocellular carcinoma \\
\hline & & Sunitinib (Sutent) & $\begin{array}{l}\text { Metastatic renal cell carcinoma, GIST (no response to } \\
\text { imatinib), pancreatic neuroendocrine tumor }\end{array}$ \\
\hline & & Pazopanib (Votrient) & Advanced renal cell carcinoma, advanced soft tissue sarcoma \\
\hline & & Dasatinib (Sprycel) & ALL, CML \\
\hline & & Axitinib (Inlyta) & Advanced renal cell carcinoma \\
\hline & & Nilotinib (Tasigna) & $\mathrm{CML}$ \\
\hline FGFRI & Fibroblast growth factor receptor I & Lenvatinib (Lenvima) & $\begin{array}{l}\text { Locally recurrent or metastatic, progressive, radioactive } \\
\text { iodine-refractory differentiated thyroid cancer }\end{array}$ \\
\hline \multirow[t]{2}{*}{ MET } & Hepatocyte growth factor receptor & Cabozantinib (COMETRIQ) & $\begin{array}{l}\text { Medullary thyroid cancer and patients with advanced RCC } \\
\text { who have received prior antiangiogenic therapy }\end{array}$ \\
\hline & & Crizotinib (XALKORI) & $\begin{array}{l}\text { Locally advanced or metastatic NSCLC that is ALK positive as } \\
\text { detected by an FDA-approved test }\end{array}$ \\
\hline \multirow[t]{2}{*}{ MTOR } & Serine/threonine protein kinase & Temsirolimus (Torisel) & Advance renal cell carcinoma \\
\hline & mTOR & Everolimus (Afinitor) & $\begin{array}{l}\text { Advanced renal cancer, subependymal giant cell astrocytoma, } \\
\text { breast cancer, pancreatic cancer }\end{array}$ \\
\hline \multirow[t]{4}{*}{ PARPI } & Poly (ADP-ribose) polymerase I & Olaparib (AZD228I) & Monotherapy in patients with deleterious or suspected \\
\hline & & & deleterious germline BRCA mutated (as detected by an \\
\hline & & & FDA-approved test) advanced ovarian cancer who have been \\
\hline & & & treated with three or more prior lines of chemotherapy \\
\hline \multirow[t]{7}{*}{ PDGFR $\alpha$} & $\begin{array}{l}\text { Platelet-derived growth factor } \\
\text { receptor alpha }\end{array}$ & Imatinib mesylate (Gleevac) & $\begin{array}{l}\text { ALL, GIST, dermatofibrosarcoma protuberans, CML, } \\
\text { myelodysplastic syndrome, systemic mastocytosis }\end{array}$ \\
\hline & & Sorafenib (Nexavar) & Advance renal cell carcinoma, some hepatocellular carcinoma \\
\hline & & Sunitinib (Sutent) & $\begin{array}{l}\text { Metastatic renal cell carcinoma, GIST (no response to } \\
\text { imatinib), pancreatic neuroendocrine tumor }\end{array}$ \\
\hline & & Pazopanib (Votrient) & Advanced renal cell carcinoma, advanced soft tissue sarcoma \\
\hline & & Nilotinib (Tasigna) & CML \\
\hline & & Axitinib (Inlyta) & Advanced renal cell carcinoma \\
\hline & & Dasatinib (Sprycel) & ALL, CML \\
\hline PSMC2 & $26 S$ protease regulatory subunit 7 & Bortezomib (Velcade) & Multiple myeloma, mantle cell lymphoma \\
\hline PSMC5 & $26 S$ protease regulatory subunit 8 & Carfilzomib (Kyprolis) & Multiple myeloma \\
\hline PSMC6 & 265 protease regulatory subunit IOB & & \\
\hline
\end{tabular}

Note: alnformation from Termglinchan et al and DrugBank Version 4.5. Republished with permission of Dovepress, from Onco Targets Ther, Candidate cancer-targeting agents identified by expression-profiling arrays, Termglinchan V, Wanichnopparat W, Suwanwongse K, et al, 6, copyright 20I3; permission conveyed through Copyright Clearance Center, Inc. ${ }^{77}$ Wishart DS, Knox C, Guo AC, et al. DrugBank: a comprehensive resource for in silico drug discovery and exploration. Nucleic Acids Res. 2006;34(Database issue):D668-D672, by permission of Oxford University Press. ${ }^{78}$

Abbreviations: FDA, Food and Drug Administration; HER2, human epidermal growth factor receptor 2; NSCLC, non-small-cell lung cancer; EGFR, epidermal growth factor receptor; ALL, acute lymphoid leukemia; GIST, gastrointestinal stromal tumor; CML, chronic myeloid leukemia; RCC, renal cell carcinoma; ALK, anaplastic lymphoma kinase. 
Table 6 Up-regulated proteins and genes that are targets of FDA-approved non-antineoplastic drugs

\begin{tabular}{|c|c|c|c|c|}
\hline Gene & Protein name & $\begin{array}{l}\text { FDA-approved } \\
\text { drug }\end{array}$ & $\begin{array}{l}\text { Drug } \\
\text { category }\end{array}$ & Disease indication $^{\mathrm{a}}$ \\
\hline $\begin{array}{l}\text { ATPIAI } \\
\text { ATPIBI }\end{array}$ & $\mathrm{Na}^{+} / \mathrm{K}^{+}-\mathrm{ATPase}$ & $\begin{array}{l}\text { Digoxin } \\
\text { Digitoxin }\end{array}$ & $\begin{array}{l}\text { Antiarrhythmia } \\
\text { agent }\end{array}$ & $\begin{array}{l}\text { For the treatment and management of congestive cardiac } \\
\text { insufficiency, arrhythmias, and heart failure. }\end{array}$ \\
\hline $\mathrm{DHODH}$ & $\begin{array}{l}\text { Dihydroorotate dehydrogenase } \\
\text { (quinone), mitochondrial }\end{array}$ & Leflunomide & $\begin{array}{l}\text { Immunosuppressive } \\
\text { agent }\end{array}$ & $\begin{array}{l}\text { For the management of the signs and symptoms of active RA. } \\
\text { Has also been used for the prevention of acute and chronic } \\
\text { rejection in recipients of solid organ trasnplants and is } \\
\text { designated by the FDA as an orphan drug for this use. }\end{array}$ \\
\hline IMPDHI & $\begin{array}{l}\text { Inosine-5'-monophosphate } \\
\text { dehydrogenase }\end{array}$ & $\begin{array}{l}\text { Mycophenolate } \\
\text { mofetil }\end{array}$ & $\begin{array}{l}\text { Immunosuppressive } \\
\text { agent }\end{array}$ & $\begin{array}{l}\text { For the prophylaxis of organ rejection in patients receiving } \\
\text { allogeneic renal, cardiac, or hepatic transplants. }\end{array}$ \\
\hline IMPDH2 & & Ribavirin & & For the treatment of chronic hepatitis C and for RSV. \\
\hline PPAT & Amidophosphoribosyltransferase & Azathioprine & $\begin{array}{l}\text { Immunosuppressive } \\
\text { agent }\end{array}$ & $\begin{array}{l}\text { For use in RA, preventing renal transplant rejection, Crohn's } \\
\text { disease, and colitis. }\end{array}$ \\
\hline
\end{tabular}

Note: anformation from Termglinchan et al and DrugBank Version 4.5.77,78

Abbreviations: FDA, Food and Drug Administration; RA, rheumatoid arthritis; RSV, respiratory syncytial virus.

lower $(0.1-1 \mu \mathrm{M})$ than the dose used for the treatment of heart disease, thereby warranting further clinical testing.

Apart from FDA-approved agents, this study also investigated various targets of chemical inhibitors (Supplementary materials). Most of the targeted proteins were catalytic enzymes (GO:0003824), in particular, the group of transferases (Figure 5). Interestingly, we found that some transferases are associated with cancer-related signaling pathways including the Wnt, MAPK, VEGF, and ErbB signaling pathways. This finding provides a list of targeted proteins that are potential candidates for further screening tests. We also identified common overexpressed proteins in the OS/OB and metastatic groups including LDHB and PKM2 as well as a shared target among all categories: CTSD (Figure 4B).

LDHB is an enzyme catalyzing the conversion of pyruvate to lactate via the glycolysis pathway. ${ }^{40}$ The association between LDHB and the etiology of OS was studied through integrated analysis of gene expression data in OS. ${ }^{41}$ The results showed higher expression of LDHB in OS tissues with single-nucleotide polymorphisms (SNPs) and copy number variants (CNVs). In addition, another study reported that high levels of serum LDH in OS was significantly related to lower overall survival. ${ }^{42}$ These all suggest a possible role of LDHB in tumorigenesis and the progression of the disease that might be linked to worsened outcomes.

PKM2 is one of the key potential targets for cancer therapy. It catalyzes the end step in the glycolysis pathway by converting phosphoenolpyruvate (PEP) to pyruvate. ${ }^{43} \mathrm{~A}$ great quantity of evidence has emerged suggesting a pivotal role of PKM2 in the metabolic phenotype of various cancers. ${ }^{44}$ Additionally, some studies have revealed the function of PKM2 as a protein kinase that is involved in cell migration and angiogenesis of colon and gastric carcinoma. ${ }^{45,46}$ Even though there have been only limited studies of the association of PKM2 and OS, this study positions PKM2 as a potential target in the treatment of OS.

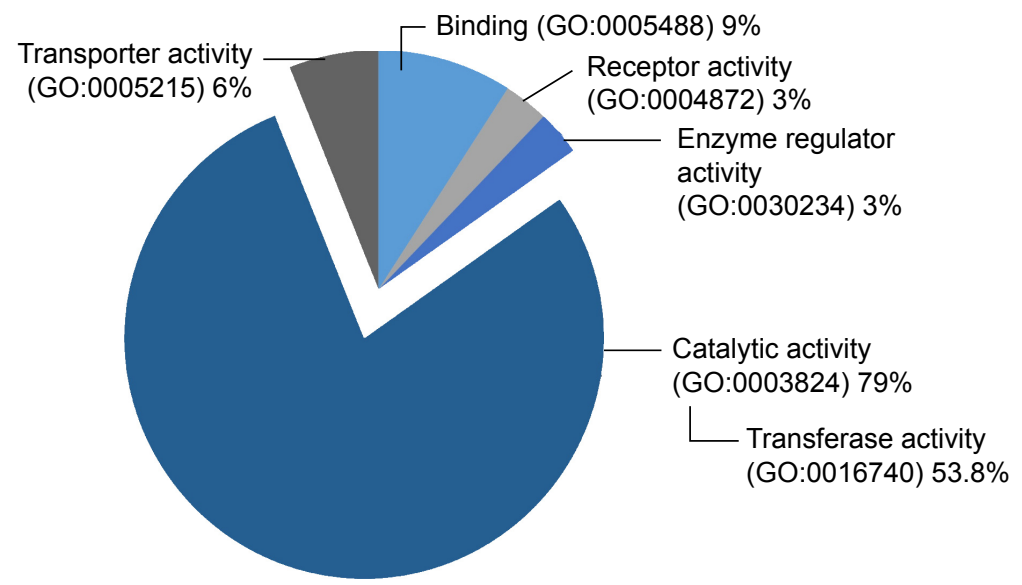

Figure 5 Groups of up-regulated proteins, targets of non-FDA-approved chemical agents.

Abbreviations: FDA, Food and Drug Administration; GO, gene ontology. 
In this study, CTSD was the only protein identified as a potential target in all experimental groups. CTSD is a lysosomal aspartic endopeptidase that plays multi-faceted roles in the normal physiological state as well as in the pathogenesis of diverse diseases..$^{47}$ Furthermore, many studies have demonstrated roles of CTSD in a wide range of cancers. It seems like this lysosomal enzyme is involved in multiple stages of tumorigenesis as well as in the progression of the disease including cell proliferation, invasion, angiogenesis, and metastasis. ${ }^{48}$ Increased expression of CTSD in OS, lung metastases, and chemoresistance are evidence that CTSD has important functions in pathological processes of OS.

\section{Conclusion}

With a growing understanding of biological mechanisms, the oncogenic driver of various cancers is being unveiled, leading to the development of a wide variety of targeted medicines. In addition, advancement in proteomics with the emergence of big data has identified key events in tumorigenesis. Therapeutic agents identified by protein expression profiles in OS were explored through a text mining and systemic review of proteomics data set. As the result, we successfully identified and explored 1) potential anticancer drugs for targeting OS-related pathways, 2) non-cancer drug repurposing, and 3) new targets for the treatment of OS. The use of targeted therapy alone or in a combination regimen as well as testing the effectiveness of drug repurposing in clinical trials can be beneficial for OS patients, especially for those who experience relapse after the use of conventional therapeutic options.

\section{Acknowledgments}

We would like to thank Prof Apiwat Mutirangura for his valuable advice. This study was supported by the National Science and Technology Development Agency (NSTDA), code P-1550265, Faculty of Medicine, Chiang Mai University, National Research University (NRU) fund, and the Excellence Center in Osteology Research and Training Center (ORTC). The authors would also like to express their sincere thanks to Dr G Lamar Robert and Assoc Prof Chongchit Sripun Robert for editing the English manuscript. The abstract (not full version) of this paper was presented at the conference, RCOST\&AOA 2016, as an oral presentation with interim findings. The abstract was published in "RCOST\&AOA 2016 Abstract book".

\section{Disclosure}

The authors report no conflicts of interest in this work.

\section{References}

1. Settakorn J, Lekawanvijit S, Arpornchayanon O, et al. Spectrum of bone tumors in Chiang Mai University Hospital, Thailand according to WHO classification 2002: a study of 1,001 cases. J Med Assoc Thai. 2006; 89(6):780-787.

2. Friebele JC, Peck J, Pan X, Abdel-Rasoul M, Mayerson JL. Osteosarcoma: a meta-analysis and review of the literature. Am J Orthop (Belle Mead NJ). 2015;44(12):547-553.

3. Allison DC, Carney SC, Ahlmann ER, et al. A meta-analysis of osteosarcoma outcomes in the modern medical era. Sarcoma. 2012;2012: 704872 .

4. Moore DD, Luu HH. Osteosarcoma. Cancer Treat Res. 2014;162: 65-92.

5. Moriarity BS, Otto GM, Rahrmann EP, et al. A sleeping beauty forward genetic screen identifies new genes and pathways driving osteosarcoma development and metastasis. Nat Genet. 2015;47(6):615-624.

6. Chen X, Bahrami A, Pappo A, et al. Recurrent somatic structural variations contribute to tumorigenesis in pediatric osteosarcoma. Cell Rep. 2014;7(1):104-112.

7. Hanash S, Taguchi A. The grand challenge to decipher the cancer proteome. Nat Rev Cancer. 2010;10(9):652-660.

8. Shukla HD, Mahmood J, Vujaskovic Z. Integrated proteo-genomic approach for early diagnosis and prognosis of cancer. Cancer Lett. 2015; 369(1):28-36.

9. Larance M, Lamond AI. Multidimensional proteomics for cell biology. Nat Rev Mol Cell Biol. 2015;16(5):269-280.

10. Gene Ontology C. Gene Ontology Consortium: going forward. Nucleic Acids Res. 2015;43(Database issue):D1049-D1056.

11. Mi H, Poudel P, Muruganujan A, Casagrande JT, Thomas PD. PANTHER version 10: expanded protein families and functions, and analysis tools. Nucl Acids Res. 2015.

12. Huang da W, Sherman BT, Lempicki RA. Systematic and integrative analysis of large gene lists using DAVID bioinformatics resources. Nat Protoc. 2009;4(1):44-57.

13. Termglinchan V, Wanichnopparat W, Suwanwongse K, et al. Candidate cancer-targeting agents identified by expression-profiling arrays. Onco Targets Ther. 2013;6:447-458.

14. Pruksakorn D, Teeyakasem P, Klangjorhor J, et al. Overexpression of $\mathrm{KH}$-type splicing regulatory protein regulates proliferation, migration, and implantation ability of osteosarcoma. Int J Oncol. 2016;49(3):10.

15. Spreafico A, Frediani B, Capperucci C, et al. A proteomic study on human osteoblastic cells proliferation and differentiation. Proteomics. 2006; 6(12):3520-3532.

16. Guo QC, Shen JN, Jin S, et al. Comparative proteomic analysis of human osteosarcoma and SV40-immortalized normal osteoblastic cell lines. Acta Pharmacol Sin. 2007;28(6):850-858.

17. Folio C, Mora MI, Zalacain M, et al. Proteomic analysis of chemonaive pediatric osteosarcomas and corresponding normal bone reveals multiple altered molecular targets. J Proteome Res. 2009;8(8):3882-3888.

18. Liu X, Zeng B, Ma J, Wan C. Comparative proteomic analysis of osteosarcoma cell and human primary cultured osteoblastic cell. Cancer Invest. 2009;27(3):345-352.

19. Zhang Z, Zhang L, Hua Y, et al. Comparative proteomic analysis of plasma membrane proteins between human osteosarcoma and normal osteoblastic cell lines. BMC Cancer. 2010;10:206.

20. PosthumaDeboer J, Piersma SR, Pham TV, et al. Surface proteomic analysis of osteosarcoma identifies EPHA2 as receptor for targeted drug delivery. Br J Cancer. 2013;109(8):2142-2154.

21. Gemoll T, Epping F, Heinrich L, et al. Increased cathepsin D protein expression is a biomarker for osteosarcomas, pulmonary metastases and other bone malignancies. Oncotarget. 2015;6(18):16517-16526.

22. Hua Y, Jia X, Sun M, et al. Plasma membrane proteomic analysis of human osteosarcoma and osteoblastic cells: revealing NDRG1 as a marker for osteosarcoma. Tumour Biol. 2011;32(5):1013-1021.

23. Yu D, Kahen E, Cubitt CL, et al. Identification of synergistic, clinically achievable, combination therapies for osteosarcoma. Sci Rep. 2015;5:16991. 
24. Grignani G, Palmerini E, Dileo P, et al. A phase II trial of sorafenib in relapsed and unresectable high-grade osteosarcoma after failure of standard multimodal therapy: an Italian Sarcoma Group study. Ann Oncol. 2012;23(2):508-516.

25. Grignani G, Palmerini E, Ferraresi V, et al. Sorafenib and everolimus for patients with unresectable high-grade osteosarcoma progressing after standard treatment: a non-randomised phase 2 clinical trial. Lancet Oncol. 2015;16(1):98-107.

26. Kubo T, Piperdi S, Rosenblum J, et al. Platelet-derived growth factor receptor as a prognostic marker and a therapeutic target for imatinib mesylate therapy in osteosarcoma. Cancer. 2008;112(10):2119-2129.

27. Gobin B, Moriceau G, Ory B, et al. Imatinib mesylate exerts anti-proliferative effects on osteosarcoma cells and inhibits the tumour growth in immunocompetent murine models. PLoS One. 2014;9(3):e90795.

28. Bond M, Bernstein ML, Pappo A, et al. A phase II study of imatinib mesylate in children with refractory or relapsed solid tumors: a Children's Oncology Group study. Pediatr Blood Cancer. 2008;50(2):254-258.

29. Chugh R, Wathen JK, Maki RG, et al. Phase II multicenter trial of imatinib in 10 histologic subtypes of sarcoma using a Bayesian hierarchical statistical model. J Clin Oncol. 2009;27(19):3148-3153.

30. Thamilselvan V, Menon M, Thamilselvan S. Carmustine enhances the anticancer activity of selenite in androgen-independent prostate cancer cells. Cancer Manag Res. 2012;4:383-395.

31. Kuo CC, Liu TW, Chen LT, et al. Combination of arsenic trioxide and BCNU synergistically triggers redox-mediated autophagic cell death in human solid tumors. Free Radic Biol Med. 2011;51(12):2195-2209.

32. Scotlandi K, Baldini N, Oliviero M, et al. Expression of Met/hepatocyte growth factor receptor gene and malignant behavior of musculoskeletal tumors. Am J Pathol. 1996;149(4):1209-1219.

33. Patane S, Avnet S, Coltella N, et al. MET overexpression turns human primary osteoblasts into osteosarcomas. Cancer Res. 2006;66(9): 4750-4757.

34. Paul SM, Mytelka DS, Dunwiddie CT, et al. How to improve R\&D productivity: the pharmaceutical industry's grand challenge. Nat Rev Drug Discov. 2010;9(3):203-214.

35. Gupta SC, Sung B, Prasad S, Webb LJ, Aggarwal BB. Cancer drug discovery by repurposing: teaching new tricks to old dogs. Trends Pharmacol Sci. 2013;34(9):508-517.

36. Zhu S, Yan X, Xiang Z, Ding HF, Cui H. Leflunomide reduces proliferation and induces apoptosis in neuroblastoma cells in vitro and in vivo. PLoS One. 2013;8(8):e71555.

37. Alhefdhi A, Burke JF, Redlich A, Kunnimalaiyaan M, Chen H. Leflunomide suppresses growth in human medullary thyroid cancer cells. J Surg Res. 2013;185(1):212-216.

38. Ko YJ, Small EJ, Kabbinavar F, et al. A multi-institutional phase ii study of SU101, a platelet-derived growth factor receptor inhibitor, for patients with hormone-refractory prostate cancer. Clin Cancer Res. 2001;7(4):800-805.

39. Elbaz HA, Stueckle TA, Tse W, Rojanasakul Y, Dinu CZ. Digitoxin and its analogs as novel cancer therapeutics. Exp Hematol Oncol. 2012;1(1):4

40. Gallo M, Sapio L, Spina A, Naviglio D, Calogero A, Naviglio S. Lactic dehydrogenase and cancer: an overview. Front Biosci (Landmark Ed). 2015;20:1234-1249.

41. Xiong Y, Wu S, Du Q, Wang A, Wang Z. Integrated analysis of gene expression and genomic aberration data in osteosarcoma (OS). Cancer Gene Ther. 2015;22(11):524-529.

42. Durnali A, Alkis N, Cangur S, et al. Prognostic factors for teenage and adult patients with high-grade osteosarcoma: an analysis of 240 patients. Med Oncol. 2013;30(3):624.

43. Mazurek S. Pyruvate kinase type M2: a key regulator of the metabolic budget system in tumor cells. Int J Biochem Cell Biol. 2011;43(7): 969-980.

44. Chaneton B, Gottlieb E. Rocking cell metabolism: revised functions of the key glycolytic regulator PKM2 in cancer. Trends Biochem Sci. 2012;37(8):309-316.
45. Zhou CF, Li XB, Sun H, et al. Pyruvate kinase type M2 is upregulated in colorectal cancer and promotes proliferation and migration of colon cancer cells. IUBMB Life. 2012;64(9):775-782.

46. Wang LY, Liu YP, Chen LG, et al. Pyruvate kinase M2 plays a dual role on regulation of the EGF/EGFR signaling via E-cadherin-dependent manner in gastric cancer cells. PLoS One. 2013;8(6):e67542.

47. Hasilik A, Neufeld EF. Biosynthesis of lysosomal enzymes in fibroblasts. Synthesis as precursors of higher molecular weight. J Biol Chem. 1980;255(10):4937-4945.

48. Benes P, Vetvicka V, Fusek M. Cathepsin D-many functions of one aspartic protease. Crit Rev Oncol Hematol. 2008;68(1):12-28.

49. Suehara Y, Kondo T, Fujii K, et al. Proteomic signatures corresponding to histological classification and grading of soft-tissue sarcomas. Proteomics. 2006;6(15):4402-4409.

50. Kawai A, Kondo T, Suehara Y, Kikuta K, Hirohashi S. Global proteinexpression analysis of bone and soft tissue sarcomas. Clin Orthop Relat Res. 2008;466(9):2099-2106.

51. Li Y, Liang Q, Wen YQ, et al. Comparative proteomics analysis of human osteosarcomas and benign tumor of bone. Cancer Genet Cytogenet. 2010;198(2):97-106.

52. Rao UN, Hood BL, Jones-Laughner JM, Sun M, Conrads TP. Distinct profiles of oxidative stress-related and matrix proteins in adult bone and soft tissue osteosarcoma and desmoid tumors: a proteomics study. Hum Pathol. 2013;44(5):725-733.

53. Bona A, Papai Z, Maasz G, et al. Mass spectrometric identification of ancient proteins as potential molecular biomarkers for a 2000-year-old osteogenic sarcoma. PLoS One. 2014;9(1):e87215.

54. Flores RJ, Li Y, Yu A, et al. A systems biology approach reveals common metastatic pathways in osteosarcoma. BMC Syst Biol. 2012; 6:50.

55. Chen X, Yang TT, Zhou Y, et al. Proteomic profiling of osteosarcoma cells identifies ALDOA and SULT1A3 as negative survival markers of human osteosarcoma. Mol Carcinog. 2014;53(2):138-144.

56. Tang J, Shen L, Yang Q, Zhang C. Overexpression of metadherin mediates metastasis of osteosarcoma by regulating epithelial-mesenchymal transition. Cell Prolif. 2014;47(5):427-434

57. Arai K, Sakamoto R, Kubota D, Kondo T. Proteomic approach toward molecular backgrounds of drug resistance of osteosarcoma cells in spheroid culture system. Proteomics. 2013;13(15):2351-2360.

58. Kubota D, Mukaihara K, Yoshida A, Tsuda H, Kawai A, Kondo T. Proteomics study of open biopsy samples identifies peroxiredoxin 2 as a predictive biomarker of response to induction chemotherapy in osteosarcoma. J Proteomics. 2013;91:393-404.

59. Izbicka E, Campos D, Marty J, Carrizales G, Mangold G, Tolcher A. Molecular determinants of differential sensitivity to docetaxel and paclitaxel in human pediatric cancer models. Anticancer Res. 2006;26(3A): 1983-1988.

60. Kang JH, Park KK, Lee IS, et al. Proteome analysis of responses to ascochlorin in a human osteosarcoma cell line by 2-D gel electrophoresis and MALDI-TOF MS. J Proteome Res. 2006;5(10):2620-2631.

61. Chang YC, Park WH, Min KS, Kim T, Kim CH, Kang JH. Proteome profiling of U2OS cell line in response to a prenylphenol antibiotic isolated from a phytopathogenic fungus. Biol Pharm Bull. 2008; 31(9):1696-1703.

62. Xie XB, Yin JQ, Wen LL, et al. Critical role of heat shock protein 27 in bufalin-induced apoptosis in human osteosarcomas: a proteomic-based research. PLoS One. 2012;7(10):e47375.

63. Kansara M, Teng MW, Smyth MJ, Thomas DM. Translational biology of osteosarcoma. Nat Rev Cancer. 2014;14(11):722-735.

64. Sau A, Filomeni G, Pezzola S, et al. Targeting GSTP1-1 induces JNK activation and leads to apoptosis in cisplatin-sensitive and -resistant human osteosarcoma cell lines. Mol Biosyst. 2012;8(4): 994-1006.

65. Klevebring D, Fagerberg L, Lundberg E, Emanuelsson O, Uhlen M, Lundeberg J. Analysis of transcript and protein overlap in a human osteosarcoma cell line. BMC Genomics. 2010;11:684. 
66. Kirkwood KJ, Ahmad Y, Larance M, Lamond AI. Characterization of native protein complexes and protein isoform variation using sizefractionation-based quantitative proteomics. Mol Cell Proteomics. 2013;12(12):3851-3873.

67. Gemei M, Corbo C, D’Alessio F, Di Noto R, Vento R, Del Vecchio L. Surface proteomic analysis of differentiated versus stem-like osteosarcoma human cells. Proteomics. 2013;13(22):3293-3297.

68. Larance M, Ahmad Y, Kirkwood KJ, Ly T, Lamond AI. Global subcellular characterization of protein degradation using quantitative proteomics. Mol Cell Proteomics. 2013;12(3):638-650.

69. Niforou KM, Anagnostopoulos AK, Vougas K, Kittas C, Gorgoulis VG, Tsangaris GT. The proteome profile of the human osteosarcoma U2OS cell line. Cancer Genomics Proteomics. 2008;5(1):63-78.

70. Li G, Zhang W, Zeng H, et al. An integrative multi-platform analysis for discovering biomarkers of osteosarcoma. BMC Cancer. 2009;9:150.

71. Li Y, Dang TA, Shen J, et al. Identification of a plasma proteomic signature to distinguish pediatric osteosarcoma from benign osteochondroma. Proteomics. 2006;6(11):3426-3435
72. Li Y, Dang TA, Shen J, et al. Plasma proteome predicts chemotherapy response in osteosarcoma patients. Oncol Rep. 2011;25(2):303-314.

73. Savitskaya YA, Rico-Martinez G, Linares-Gonzalez LM, et al. Serum tumor markers in pediatric osteosarcoma: a summary review. Clin Sarcoma Res. 2012;2:9.

74. Jin S, Shen JN, Guo QC, et al. 2-D DIGE and MALDI-TOF-MS analysis of the serum proteome in human osteosarcoma. Proteomics Clin Appl. 2007;1(3):272-285.

75. Kanehisa M, Goto S. KEGG: Kyoto encyclopedia of genes and genomes. Nucleic Acids Res. 2000;28:27-30.

76. Nishimura D. Biotech Software \& Internet Report. NY: Mary Ann Liebert, Inc. 2001;2(3):117-120.

77. Termglinchan V, Wanichnopparat W, Suwanwongse K, et al. Candidate cancer-targeting agents identified by expression-profiling arrays. Onco Targets Ther. 2013;6:447-458.

78. Wishart DS, Knox C, Guo AC, et al. DrugBank: a comprehensive resource for in silico drug discovery and exploration. Nucleic Acids Res. 2006;34(Database issue):D668-D672.
OncoTargets and Therapy

\section{Publish your work in this journal}

OncoTargets and Therapy is an international, peer-reviewed, open access journal focusing on the pathological basis of all cancers, potential targets for therapy and treatment protocols employed to improve the management of cancer patients. The journal also focuses on the impact of management programs and new therapeutic agents and protocols on

\section{Dovepress}

patient perspectives such as quality of life, adherence and satisfaction. The manuscript management system is completely online and includes a very quick and fair peer-review system, which is all easy to use. Visit http://www.dovepress.com/testimonials.php to read real quotes from published authors. 